\title{
Within-session changes in responding during delayed matching-to-sample and discrimination procedures
}

\author{
FRANCES K. MCSWEENEY, JEFFREY N. WEATHERLY, and SAMANTHA SWINDELL \\ Washington State University, Pullman, Washington
}

\begin{abstract}
Two experiments examined within-session changes in responding during discrimination procedures. In Experiment 1, rate of responding changed significantly within sessions during symbolic delayed matching-to-sample tasks when the delay between the stimulus and the choice period was short (1-5 sec), but not when it was long (8-12 sec). The percentage of responses that were correct did not change within sessions. In Experiment 2, response rates increased and then decreased within sessions during both $\mathrm{S}+$ and $\mathrm{S}-$ when successive discrimination procedures provided high, but not low, rates of reinforcement. Discrimination ratios sometimes increased within sessions. These results question two potential definitions of attention as explanations for within-session changes in response rates. They are more compatible with explanations based on concepts such as arousal, satiation, habituation, and interfering responses.
\end{abstract}

Response rate averaged across the experimental session is a frequently used dependent variable in studies of operant conditioning (Herrnstein, 1970). Recently, exclusive reliance on average measures has been questioned by the observation of large and systematic changes in responding within experimental sessions (e.g., McSweeney \& Roll, 1993). Although these changes have been known for many years, they have been treated as problems to be controlled by procedures, such as giving "warm-up" trials (e.g., Hodos \& Bonbright, 1972) and time to adapt to the apparatus (e.g., Papini \& Overmier, 1985).

Further consideration suggests that within-session changes in responding deserve study in their own right. These changes may be large and orderly, appearing for individual subjects responding in individual sessions (e.g., McSweeney \& Hinson, 1992). They may occur throughout the session, not just at the beginning (e.g., McSweeney, Hatfield, \& Allen, 1990). They occur for a wide variety of species, procedures, responses, and reinforcers (e.g., McSweeney \& Roll, 1993). Finally, they may have a number of important theoretical and methodological implications (e.g., McSweeney \& Roll, 1993).

The present experiments examined within-session changes in responding during symbolic delayed matchingto-sample (DMTS) procedures (Experiment 1) and during multiple variable-interval (VI) extinction schedules (Experiment 2). They had two goals. First, within-session

This material is based on work supported by National Science Foundation Grant IBN-9403719. Some of these results were presented at the November 1994 meeting of the Psychonomic Society in St. Louis, MO. Correspondence should be addressed to F. K. McSweeney, Department of Psychology, Washington State University, Pullman, WA 99164-4820. changes have not been studied systematically during procedures that involve discrimination. Therefore, these experiments might extend the generality of within-session changes to two new procedures. Extending their generality is important. If within-session changes occur only under limited conditions, then they would reflect processes peculiar to those conditions. If they occur more generally, they may reflect more important processes.

Second, the experiments may help to identify the classes of variables that produce within-session changes in response rates. The study of within-session changes is only beginning. Therefore, existing data cannot test precise theoretical explanations for these changes. The data can, however, separate broad classes of explantions that can be specified more precisely by further experiments. DMTS and successive discrimination procedures provide measures of both the rate and the accuracy of responding. As will be discussed, the question of whether response accuracy changes systematically within sessions has potential implications for identifying the types of variables that produce within-session changes in response rates.

\section{EXPERIMENT 1}

Experiment 1 employed a DMTS task. During DMTS procedures, a sample stimulus is presented. A choice period follows this sample after a delay. During the choice period, one response is correct if one sample stimulus was presented; a different response is correct if the other sample was presented. Correct responses are followed by reinforcers. Either incorrect responses end the trial without reinforcement (noncorrection procedure) or the subject is allowed to collect the reinforcer by making an additional correct response (correction procedure). Responding on the sample stimulus provides a measure of rate of respond- 
ing. The percentage of correct responses during the choice period provides a measure of response accuracy.

At least one explanation for within-session changes in response rates predicts that the accuracy of responding should change within sessions. Within-session changes in response rates might be attributed to changes in subjects' "attention" to the instrumental task. Because changes in the accuracy of responding during DMTS procedures are assumed to reflect changes in attention (e.g., McCarthy \& Voss, 1995), response accuracy-not just response rate-should change systematically within sessions.

Several other potential explanations provide no reason to expect that response accuracy will change within sessions. The early-session increases in responding might be attributed to the accumulation of arousal with the presentation of reinforcers (e.g., Killeen, Hanson, \& Osborne, 1978), to decreases in responses (such as exploration) that are evoked by placement in the experimental enclosure and that interfere with instrumental responding (e.g., Bindra, 1959; Feldman, 1963; Glanzer, 1958), or to sensitization (e.g., Groves \& Thompson, 1970). The late-session decreases in responding might be attributed to the waning of arousal as the session progresses, to increases in interfering responses (e.g., Pavlov, 1928), to habituation (e.g., Groves \& Thompson, 1970), or to satiation (e.g., Reese \& Hogenson, 1962).

These concepts are not entirely well defined, and each of them could be applied to the current situation in a variety of ways. Nevertheless, each can be interpreted in such a way that it predicts that the accuracy of responding will not change within the session. For example, arousal might be represented by a multiplicative parameter in an equation that describes responding (e.g., Killeen et al., 1978). If this parameter multiplies all responding, then a measure of response accuracy (such as percent correct) that is based on the ratio of correct to total (correct plus incorrect) responding should remain constant within sessions. Within-session changes in arousal should cancel when ratio measures are taken.

The present experiment studied responding during DMTS procedures that employed both correction and noncorrection procedures. Employing both procedures increased the generality of the results. It also tested one potential explanation for a failure of accuracy to change within sessions during a correction procedure. Subjects could collect reinforcers by switching to the correct key during a correction procedure even if they responded first on the incorrect key. Noncorrection procedures in which the trial was terminated and reinforcers were cancelled after an incorrect response more severely penalized incorrect responding. Therefore, it was possible that they might yield more sensitive measures of changes in attention.

\section{Method}

Subjects. Ten experimentally experienced pigeons, exposed to a 12:12-h light:dark cycle, served as subjects. They were maintained at approximately $85 \%$ of their free-feeding body weights by postsession feedings.
Apparatus. The apparatus was a three-key experimental enclosure for pigeons, measuring $30 \times 36 \times 27 \mathrm{~cm}$. The three $2.5-\mathrm{cm}$ diameter response keys were located $21.5 \mathrm{~cm}$ above the floor and $7.5 \mathrm{~cm}$ apart. The left key appeared $7 \mathrm{~cm}$ from the left wall; the right key was $7.5 \mathrm{~cm}$ from the right wall. A force of approximately $0.25 \mathrm{~N}$ was required to operate each key. A $4.5 \times 5 \mathrm{~cm}$ opening allowed access to a magazine containing mixed grain. It was located $7.5 \mathrm{~cm}$ above the floor and $15 \mathrm{~cm}$ from the right wall. A 4-cmdiameter houselight was located $1.5 \mathrm{~cm}$ from the ceiling and $0.5 \mathrm{~cm}$ from the right wall. The experimental panel was housed in a sound-attenuating chamber. A ventilating fan masked noises from outside the chamber. At different times, experimental events were programmed by a SYM microcomputer or by a MED Associates interface connected to an IBM-compatible personal computer, located in another room.

Procedure. For all subjects, a trial started when a red or green light, determined randomly, appeared on the center key. This "sample" stimulus was terminated by the first peck that occurred after $5 \mathrm{sec}$ had elapsed. The peck started a delay period that ended when the left and right keys were illuminated with white light. The illumination of these keys was terminated either by a peck or after $5 \mathrm{sec}$. A 20 -sec intertrial interval (ITI), during which the key lights were extinguished and pecks had no consequence, followed either reinforcement or the termination of the choice period. Then, the next trial began. All sessions ended after $60 \mathrm{~min}$, excluding magazine time. The houselight was illuminated throughout the session. The delay between the sample and the choice period was $1,5,12$, 8 , or $3 \mathrm{sec}$ in different conditions, presented in that order. Each condition was presented for 30 daily sessions, conducted five or six times per week.

Six subjects responded on the correction procedure. For 2 of these subjects, pecking the left key during the choice period was correct when the center key had been green. Pecking the right key was correct when the center key had been red. For the other subjects, the correct key was reversed. Pecking the incorrect key had no consequence. Correct pecks ended the trial and were followed by 5 -sec access to mixed grain.

Four subjects responded on the noncorrection procedure. For these subjects, pecking the left key during the choice period was correct when the center key had been red; pecking the right key was correct when the center key had been green. The first peck during the choice period ended the trial and started the ITI regardless of whether that peck was correct or not. Only a correct peck was followed by a reinforcer.

\section{Results and Discussion}

Figure 1 presents the number of responses on the center key (top axes) and the percent of correct responses (bottom axes) during successive 5-min intervals in the session for subjects responding during the correction (left) and noncorrection (right) procedures. The percentage of correct responses was calculated by dividing the number of responses on the correct key during the choice period by the sum of correct and incorrect responses during that period. Each function presents the results for a particular delay period, averaged over all subjects responding during the last five sessions for which that delay was presented. Table 1 presents the results of one-way (5-min interval) within-subject analyses of variance (ANOVAs) applied to the rates of responding (top) and the percentage of correct responses (bottom) for individual subjects responding on the correction and noncorrection procedures. Results were presented and analyzed in terms of 5-min intervals so that they could be 

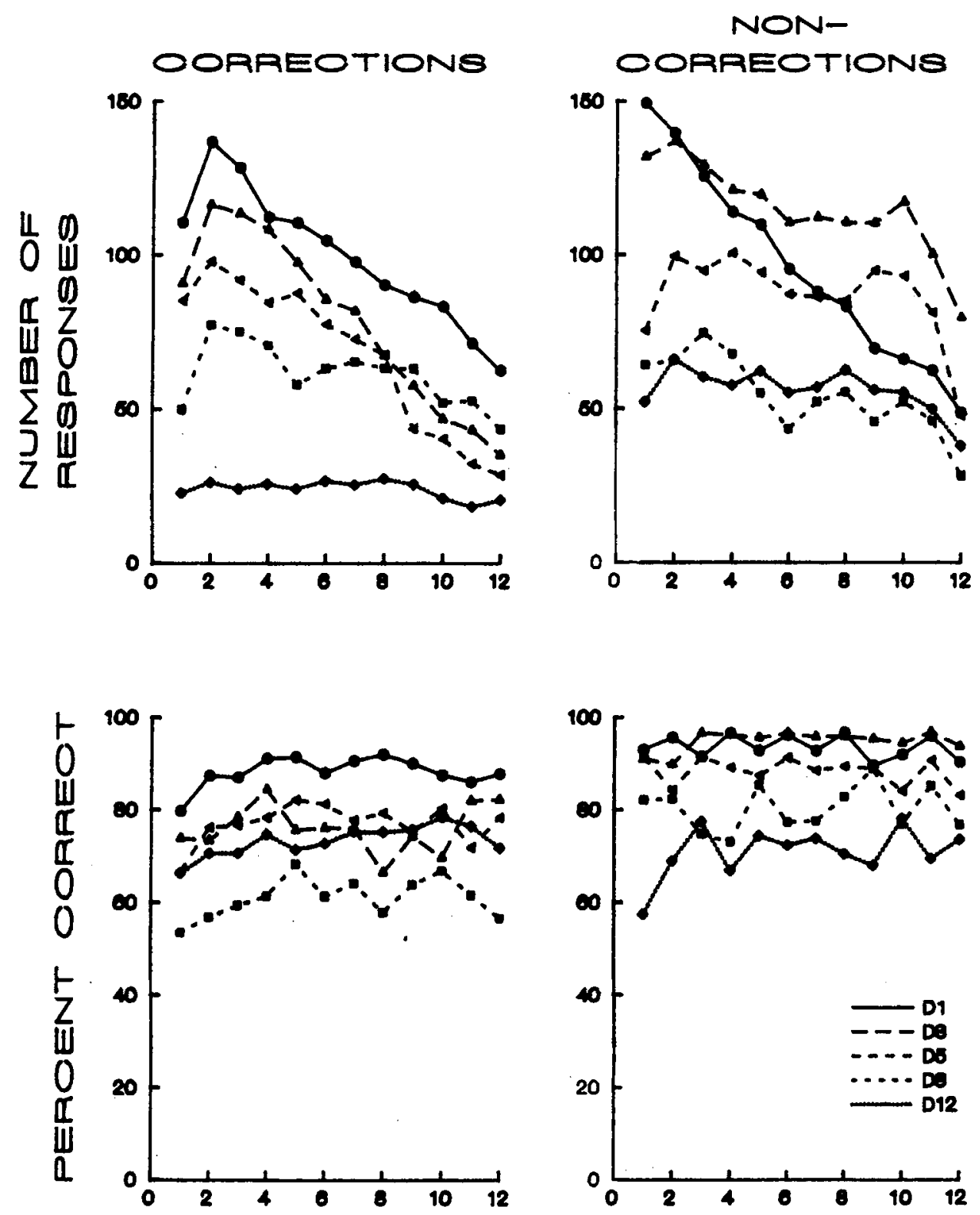

FIVE-MINUTE INTERVAL

Figure 1. Mean number of pecks on the center key (top graphs) and the percent of correct pecks (bottom graphs) during successive 5-min intervals in the session for pigeons responding on the correction (left graphs) and noncorrection (right graphs) delayed matching-to-sample procedures in Experiment 1. Each function represents the results for one delay period. All results have been averaged across all pigeons and are taken from the last 5 sessions for which each delay was presented.

compared with the results of other studies on withinsession changes in response rates.

The top graphs in Figure 1 show that response rate often decreased or increased and then decreased within sessions. These within-session changes were large at short delays and became flatter as the delay period increased. For example, the difference between the rate of responding during the fastest and slowest 5-min interval in the session was $74.3,81.1,69.5,33.8$, and 9.2 responses for the mean of all subjects responding on the correction pro- cedure at the 1-, 3-, 5-, 8-, and 12-sec delays, respectively. Results for the subjects responding on the noncorrection procedure were $100.7,57.4,52.9,46.3$, and 28.0 responses for the same delays presented in the same order.

Figure 1 also shows that the within-session changes in response rates were not accompanied by similar changes in response accuracy (percent correct). The within-session changes in percent correct (bottom graphs) were smaller and did not display systematic trends. 
Table 1

Results ( $F$ Values) of One-Way (5-Min Interval) Within-Subject ANOVAs Applied to Response Rates and Percent Correct During the Correction and Noncorrection DMTS Procedures in Experiment 1

\begin{tabular}{lccccc}
\hline \multirow{2}{*}{ Procedure } & 1 & 3 & 5 & 8 & 12 \\
\cline { 2 - 6 } & \multicolumn{5}{c}{ Response Rate } \\
Correction & $3.76_{+}^{+}$ & $4.05 \ddagger$ & 1.84 & 1.23 & 1.33 \\
Noncorrection & $2.19^{*}$ & 1.39 & $2.92 \dagger$ & 1.01 & 0.44 \\
& \multicolumn{5}{c}{ Percent Correct } \\
Correction & 1.33 & 1.66 & 1.40 & 1.01 & 1.13 \\
Noncorrection & 0.96 & 0.86 & 0.40 & 0.91 & $2.32^{*}$ \\
\hline
\end{tabular}

Note-For the correction DMTS procedure, all $d f \mathrm{~s}=11,55$. For the noncorrection DMTS procedure, all $d f \mathrm{~s}=11,33 .{ }^{*} p<.05 . \quad \dagger p<$ $01 . \neq p<.001$.

Table 1 confirms these visual impressions. The withinsession changes in the response rates were significant $(p<.05)$ when the delay between the stimulus and choice period was short ( $1-5 \mathrm{sec})$, but not when it was long $(8-12 \mathrm{sec})$. Response accuracy did not change significantly within sessions for any condition except the 12sec delay when the subjects responded on the noncorrection procedure. This significant change was produced by the low accuracy of responding during the first 5-min interval for that condition. When responding during the first 5-min interval was excluded, accuracy did not change significantly within sessions $[F(10,30)=1.37]$. The failure to find similar within-session changes for the rate and accuracy of responding is particularly convincing because the measures of response rate and response accuracy reported in Figure 1 were obtained from the same subjects responding during the same sessions.

The failure to find within-session changes in response accuracy is consistent with the results of some past studies. Wilkie (1986) found that the percentage of correct responses did not change as a function of blocks of trials in the session when pigeons responded on a spatial DMTS procedure. Edhouse and White (1988) reported that the percentage of correct responses did not change significantly within sessions when pigeons responded on a DMTS procedure, although the percent correct was somewhat lower during the first quarter of the session than it was later. Neither of these studies provided information about within-session changes in response rate.

The flatter within-session changes in response rates at longer delays in Figure 1 are consistent with results reported when subjects respond on standard schedules of reinforcement (e.g., simple and multiple schedules). Obtained rate of reinforcement decreased with increases in the present delay periods. For example, the mean obtained rates of reinforcement were 115.8, 96.1, 99.3, 79.5 , and 70.0 reinforcers per hour for the $1-, 3-, 5-, 8-$, and $12-\mathrm{sec}$ delays, respectively, when the correction procedure was used. This decrease occurred because the length of a trial increased with increases in delay, and the subjects could obtain at most one reinforcer per trial. Past studies of responding on simple and multiple sched- ules have also reported that within-session changes in response rates are flatter and less likely to be statistically significant for schedules that provide lower rates of reinforcement than for those that provide higher rates of reinforcement (e.g., McSweeney, 1992; McSweeney, Roll, \& Weatherly, 1994).

As is often found during DMTS procedures, the accuracy of responding averaged over the session decreased with increases in the delay period (e.g., Roberts, 1972). The mean percentages of correct responses during the correction procedure were 88.2, 76.0,77.0,60.9, and 73.3 for the 1-, 3-, 5-, 8-, and 12-sec delays, respectively. The mean percentages of correct responses during the noncorrection procedure were $92.6,94.8,88.1,79.4$, and 70.8 for the same delays presented in the same order. One-way within-subject ANOVAs applied to percent correct showed that the change in accuracy with changes in the length of the delay was statistically significant $(p<$ .05 ) for both the correction procedure $[F(4,20)=12.60]$ and the noncorrection procedure $[F(4,12)=8.73]$.

The absolute number of responses averaged over the session (top axes, Figure 1) also decreased with increases in the delay to reinforcement. These decreases were produced by two factors. First, the opportunity to respond decreased with increases in the delay. As indicated, trials were longer when the delay was longer. The mean numbers of trials per 5-min interval was $10.1,8.2,8.4,7.6$, and 6.0 for the 1-, 3-, 5-, 8-, and 12-sec delays, respectively. Because the center key was illuminated only once per trial, the subjects had fewer opportunities to peck this key at the longer delays. Second, as just discussed, the obtained rate of reinforcement decreased with increases in the delay, and many studies have reported that rate of responding on the sample key is governed by the reinforcers that follow correct responding (e.g., DeLong \& Wasserman, 1981; McCarthy \& Voss, 1995; Santi \& Roberts, 1985).

\section{EXPERIMENT 2}

Experiment 2 examined responding during several successive discrimination procedures. If it is assumed that responding during $\mathrm{S}+$ is "correct" and responding during $S-$ is "incorrect," then the discrimination ratio $[\mathrm{S}+/(\mathrm{S}++\mathrm{S}-)]$ provides a measure of response accuracy that is superficially similar to the percent correct measure during DMTS procedures. Therefore, successive discrimination procedures can test whether response accuracy changes within experimental sessions.

Successive discrimination procedures can also be used to determine whether the within-session changes in response rates during $\mathrm{S}+$ and $\mathrm{S}-$ occur in similar or in opposite directions. Several explanations for within-session changes in response rates predict that responding should change similarly during $\mathrm{S}+$ and $\mathrm{S}-$. For example, if arousal is represented by a multiplicative parameter in an equation that describes responding (e.g., Killeen et al., 1978), and if this parameter multiplies all responding, then responding should change similarly within the 
session regardless of whether that responding occurs during $\mathrm{S}+$ or $\mathrm{S}-$.

In contrast, one potential definition of attention predicts that responding will change in the opposite directions during $\mathrm{S}+$ and $\mathrm{S}-$. It seems reasonable to assume that subjects' behavior would be more closely controlled by the stimulus-response-reinforcer contingency when they are attending to the experimental task than when they are not. Greater control by the operant contingency should produce more responding during $\mathrm{S}+$ when responding is reinforced and less responding during $S-$ when responding is not reinforced. Therefore, if subjects' attention to the task changes systematically during the session, responding during $\mathrm{S}+$ should increase when responding during $\mathrm{S}-$ decreases, and vice versa.

A few studies have supported this prediction by reporting that responding increases during $\mathrm{S}+$ and decreases during $\mathrm{S}-$ early in experimental sessions (e.g., Tennant \& Bitterman, 1973; Woodard \& Bitterman, 1972). However, the results of these studies might be an artifact of the use of a reversal procedure in which the identity of $S+$ and $\mathrm{S}-$ changed frequently. Subjects may have responded as they did only because their responding provided a good strategy for solving the reversal problem. That is, subjects would quickly respond appropriately in reversal situations if they responded equally to both stimuli at the beginning of the session and then increased their responding to $\mathrm{S}+$ and decreased it to $\mathrm{S}-$ as it became apparent which stimulus played which role. In that case, increases in responding during $S+$ and decreases during $S-$ might be an artifact of the reversals procedure. In support of this argument, Herrnstein, Loveland, and Cable (1976) examined the behavior of pigeons responding on a concept-formation task that did not employ frequent reversals. They reported that fewer responses occurred later in the session than occurred earlier regardless of whether subjects responded on $\mathrm{S}+$ or $\mathrm{S}-$.

Experiment 2 asked whether responding changed similarly or in the opposite directions within sessions during $\mathrm{S}+$ and $\mathrm{S}-$ when these stimuli were not reversed frequently. It also asked whether the accuracy of responding, defined by the discrimination ratio, changed systematically within experimental sessions.

\section{Method}

Subjects. The subjects were 5 experimentally naive rats bred from Sprague-Dawley stock in the Johnson Tower Vivarium at Washington State University. They were approximately 120 days old at the start of the experiment and were maintained at approximately $85 \%$ of their free-feeding body weights by postsession feedings. All subjects were exposed to a 12:12-h light:dark cycle.

Apparatus. The apparatus was a standard two-lever experimental enclosure $(20 \times 24.5 \times 24.5 \mathrm{~cm})$. A $5 \times 5.5 \mathrm{~cm}$ opening, which allowed access to food, was centered on the front panel, $0.5 \mathrm{~cm}$ above the floor. Two $4 \times 1.5 \mathrm{~cm}$ levers appeared $2.5 \mathrm{~cm}$ from this opening, one on each side. The levers were $5 \mathrm{~cm}$ above the floor and extended $1.5 \mathrm{~cm}$ into the enclosure. A 2-cm-diameter light was located $2.5 \mathrm{~cm}$ above each lever. A third, 2-cm-diameter, light was centered on the front panel, $4 \mathrm{~cm}$ from the ceiling. The houselight was another 2-cm-diameter light, located in the center of the ceiling. The experimental panel was housed in a sound- attenuating chamber. A ventilating fan masked noises from outside the chamber. Experimental events were presented and data were recorded by a SYM microcomputer located in another room.

Procedure. The subjects were trained to press the right lever by a shaping-by-successive-approximations procedure. The subjects then responded on the following schedules presented in the following order: multiple VI 30 -sec ext, multiple ext VI 120-sec, multiple VI 240-sec ext, multiple ext VI $15-\mathrm{sec}$, multiple VI 60-sec ext, multiple ext VI 60-sec, multiple VI 15-sec ext, multiple ext VI 240 -sec, multiple VI $120-\mathrm{sec}$ ext, and multiple ext VI 30 -sec. Components alternated evey $5 \mathrm{~min}$, and sessions ended after 12 components had been presented $(60 \mathrm{~min})$. The light above the right lever was illuminated with white light during the component listed first. It was not illuminated during the component listed second. The houselight was illuminated throughout the session. Reinforcers (45-mg Noyes pellet) were presented according to a 25 -interval Fleshler and Hoffman (1962) series. They were obtained by pressing the right lever. Each schedule was presented for 30 sessions that were conducted daily, five or six times per week.

The reversal of the component that provided extinction every 30 sessions prevented responding from extinguishing completely. Within-session changes in responding could not be observed during $\mathrm{S}-$ if no responding occurred during that component. Each schedule was conducted twice-once with the light signaling the VI component and once with the light signaling extinction-so that results could be averaged over these conditions.

\section{Results and Discussion}

Table 2 presents the rates of responding (responses per minute) during $\mathrm{S}+$ and $\mathrm{S}-$ averaged over the session for each subject and for the mean of all subjects. Results are the means calculated over the last 5 sessions for which each schedule was available and are averaged over the two presentations of each schedule.

Table 2 shows that the rate of responding during $\mathrm{S}+$ was higher than the rate during $S-$ for all subjects except Subject 31 responding during the multiple VI $120-\mathrm{sec}$ ext schedules. The high rate of responding during $S-$ for that schedule may have occurred because it was the first reversal to be conducted. The rate of responding during $\mathrm{S}+$ also varied directly with the rate of reinforcement provided during $\mathrm{S}+$. A two-way (component $\times$ schedule) within-subject ANOVA applied to the rates of responding

Table 2

Rates of Responding (Responses per Minute) During Each Component of Each Multiple Schedule in Experiment 2

\begin{tabular}{ccrrrrr}
\hline & & \multicolumn{5}{c}{ VI (in Seconds) Extinction Schedule } \\
\cline { 3 - 7 } Subject & Component & 15 & \multicolumn{1}{c}{30} & 60 & 120 & 240 \\
\hline 31 & S+ & 8.7 & 12.5 & 3.3 & 3.1 & 2.6 \\
& S- & 0.7 & 0.4 & 1.0 & 3.1 & 0.9 \\
32 & S+ & 9.5 & 10.5 & 3.2 & 3.3 & 1.0 \\
& S- & 1.2 & 0.9 & 1.2 & 1.9 & 0.8 \\
33 & S + & 4.6 & 3.6 & 0.5 & 1.1 & 0.1 \\
& S- & 0.5 & 0.4 & 0.4 & 0.7 & 0.1 \\
34 & S+ & 8.3 & 7.4 & 2.4 & 2.0 & 0.9 \\
35 & S- & 0.5 & 1.2 & 0.8 & 0.9 & 0.8 \\
& S+ & 9.9 & 7.8 & 3.3 & 3.1 & 2.0 \\
\multirow{3}{*}{ Mean } & S- & 1.0 & 1.4 & 1.7 & 1.7 & 1.0 \\
& S+ & 8.2 & 8.4 & 2.5 & 2.5 & 1.3 \\
& S- & 0.8 & 0.9 & 1.0 & 1.7 & 0.7 \\
\hline
\end{tabular}

Note-Rates have been averaged over the two presentations of each schedule. 
by individual subjects showed that the subjects responded at significantly different $(p<.05)$ rates during $\mathrm{S}+$ and $S-$ [significant main effect of component, $F(1,4)=$ 40.93], that rate of responding changed significantly with changes in the schedule [significant main effect of schedule, $F(4,16)=42.55$ ], and that the changes in responding with changes in the schedule differed for $\mathrm{S}+$ and $S-$ [significant interaction, $F(4,16)=27.59$ ].
Figure 2 presents the percentage of the total-session responses in S + (solid line) and S- (dashed line) during successive 10-min intervals in the session. Each graph presents the results for the mean of all subjects responding on a particular schedule. Percentages were calculated by dividing the number of responses during $\mathrm{S}+(\mathrm{S}-)$ during a 10 -min interval by the total responses during $S+$ $(\mathrm{S}-)$ during the entire session and multiplying by 100 .

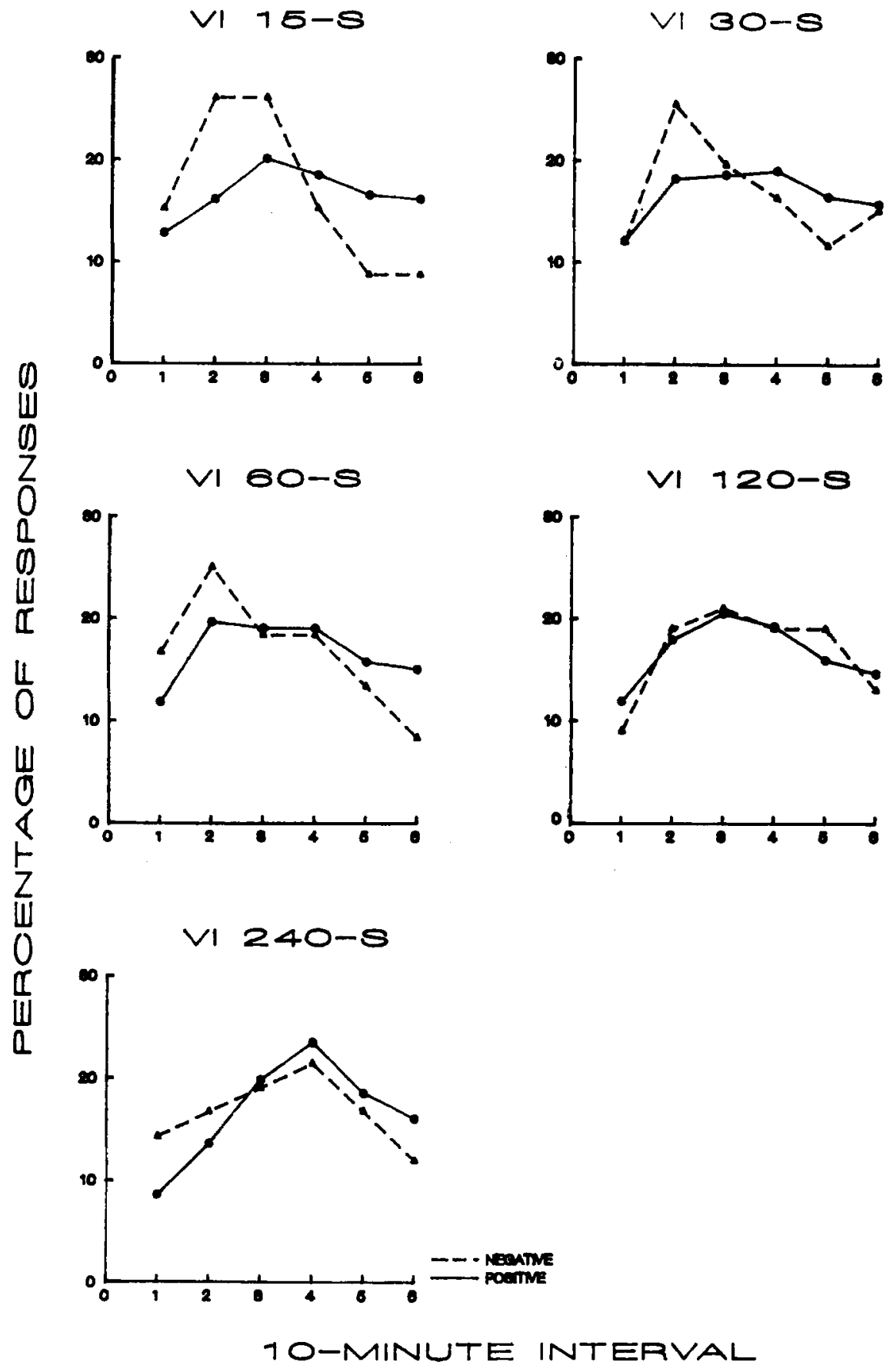

Figure 2. Percentage of total-session leverpresses by rats during successive 10-min intervals in the session for $\mathrm{S}+$ (solid line) and $\mathrm{S}-$ (dashed line) in Experiment 2. Each graph presents the results for the mean of all rats responding on a particular schedule. 
Percentages have been presented so that the large differences in the absolute rates at which the subjects responded on $\mathrm{S}+$ and $\mathrm{S}-$ (see Table 2) would not obscure similarities in the within-session changes in responding. Percentages can be converted to absolute response rates using the rates of responding averaged over the session that are presented in Table 2. Percentages were calculated over 10-min intervals, instead of over 5-min components, because $\mathrm{S}+($ or $\mathrm{S}-$ ) appeared during the first $5 \mathrm{~min}$ of each 10-min interval during one of its presentations and during the second 5 min during its other presentation.

Figure 2 shows that responding usually changed in the same direction during both $\mathrm{S}+$ and $\mathrm{S}-$. If responding increased within the session during $\mathrm{S}+$ and decreased during $\mathrm{S}-$, then the correlation between response rates during successive $S+$ and $S-$ components would be negative. If responding changed in similar ways, then correlations would be positive. Pearson correlation coefficients calculated for the rates of responding during $\mathrm{S}+$ and $S-$ in successive 10 -min intervals were $.37, .64, .58$, .92 , and .71 for the mean of all subjects responding on the multiple VI 15-sec ext, VI 30-sec ext, VI 60-sec ext, VI 120-sec ext, and VI 240-sec ext schedules, respectively.

Figure 3 presents the rate of responding (top graph) and the accuracy of responding (discrimination ratio, bottom graph) as a function of 10 -min intervals in the session. Response rate is the sum of responding during $\mathrm{S}+$ and $S-$ in responses per minute. Discrimination ratios were calculated by dividing the number of responses during $S+$ in a 10-min interval by the sum of responses during $\mathrm{S}+$ and $\mathrm{S}-$ in that 10 -min interval. Each function presents the results for one of the multiple schedules.

As in Figure 1, large within-session changes in response rates occurred when $\mathrm{S}+$ provided high rates of reinforcement (the multiple VI 15-sec ext and multiple VI 30-sec ext schedules). The within-session changes were flatter at lower programmed rates of reinforcement (see also McSweeney, 1992; McSweeney et al., 1994). As in Figure 1, the within-session changes in response rates were not accompanied by similar changes in response accuracy (discrimination ratios). The within-session changes in discrimination ratios were relatively flat for the multiple VI 15 -sec ext and multiple VI 30-sec ext schedules. They increased somewhat within sessions for the multiple VI 60sec ext and multiple VI 240-sec ext schedules, and they decreased somewhat for the multiple VI 120 -sec ext schedule.

The polynomial contrasts of one-way (10-min interval) within-subject ANOVAs confirmed that the form of the within-session changes differed for rate and accuracy of responding. The quadratic contrast was significant or nearly significant for rate of responding during the multiple VI 15 -sec ext $[F(1,4)=6.44, p<.064]$, the multiple VI 30 -sec ext $[F(1,4)=11.86, p<.026]$ and the multiple VI 60 -sec ext $[F(1,4)=5.82, p<.073]$ schedules. The linear contrast was significant or nearly significant for discrimination ratios during the multiple VI 15 -sec ext $[F(1,4)=14.12, p<.020]$, the multiple VI $60-\sec$ ext $\lceil F(1.3)=15.27 .0<.0301$ and the multible
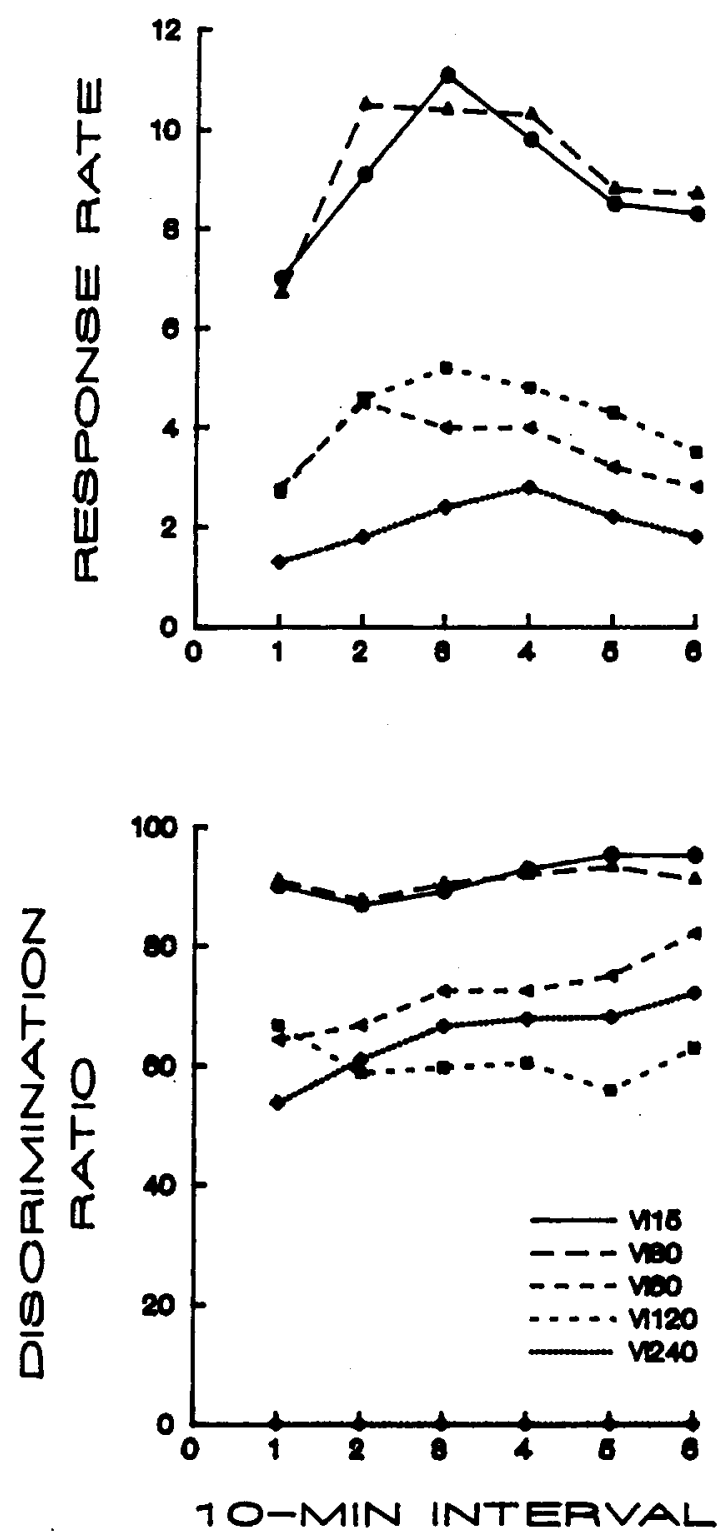

Figure 3. Sum of rates of responding during $S+$ and $S-$ (top graph) and discrimination ratios (bottom graph) during successive 10-min intervals in the session in Experiment 2. Each function presents the results for the mean of all rats responding on a particular schedule.

VI 240 -sec ext $[F(1,3)=7.32, p<.073]$ schedules. These results indicate that the within-session changes in response rates were bitonic in form; the within-session changes in discrimination ratios were linear. The degrees of freedom for discrimination ratios were smaller for the multiple VI 60 -sec ext and multiple VI 240 -sec ext schedules than for the multiple VI 15 -sec ext schedule because 1 subject did not respond throughout the session during the schedules that provided lower rates of reinforcement. The results for that subject were not included in the statistical tests because discrimination ratios could not be calculated for all 10 -min intervals within the session. 


\section{GENERAL DISCUSSION}

The present results extend the generality of withinsession changes in response rates to two new procedures: DMTS and discrimination. They also suggest that similar factors produce the within-session changes during both discrimination and nondiscrimination procedures. Figures 1 and 3 show that the present within-session changes became flatter as the rate of reinforcement decreased. A similar flattening in the within-session changes with decreases in the rate of reinforcement has been reported when subjects respond on simple (e.g., McSweeney et al., 1994) and multiple VI VI (e.g., McSweeney, 1992) schedules. Finding similar changes in the form of the within-session patterns when an independent variable is manipulated suggests a common explanation for the patterns (e.g., Bitterman, 1960, 1965). Although one or two similarities might occur by chance, similar functional changes are unlikely to occur accidentally.

The present results showed that responding changed similarly, not in the opposite direction, within sessions during the $\mathrm{S}+$ and $\mathrm{S}-$ of several successive discrimination procedures (Figure 2). They also showed that the withinsession changes in response rates were not accompanied by similar changes in response accuracy (Figures 1 and 3). Accuracy often failed to change significantly within sessions, and, when it did change, the within-session pattern was not similar in form to the within-session pattern reported for response rate. This finding has some generality. It was reported for both pigeons (Experiment 1 ) and rats (Experiment 2), for DMTS and successive discrimination procedures, for correction and noncorrection DMTS procedures, for two different measures of response accuracy (percent correct and discrimination ratios), and for procedures conducted using several different rates of reinforcement.

Taken together, the present results question whether within-session changes in response rates are produced by changes in attention to the operant task, at least when attention is defined in two different ways. First, it is often assumed that the accuracy of responding during a DMTS procedure provides an index of attention to the task (e.g., McCarthy \& Voss, 1995). In that case, Figure 1 shows that attention to the task did not change within experimental sessions. Second, the operant contingency might exert greater control over behavior when subjects are attending to the instrumental task than when they are not. In that case, Figure 2 shows that attention did not change within experimental sessions. Greater control by the operant contingency should be expressed by an increase in responding during $S+$, when responding is reinforced, and by a decrease in responding during $\mathrm{S}-$, when responding is not reinforced. Therefore, response rates should have changed in the opposite direction during $\mathrm{S}+$ and $\mathrm{S}-$ if control by the operant contingency changed during the session. This was not observed.

McSweeney et al. (1994) also failed to find a change in control by the operant contingency within experimental sessions. They studied responding on several variable ratio (VR), fixed-interval (FI), and differential reinforcement of low rates of responding (DRL) schedules. Responding generally decreased within sessions regardless of whether subjects responded on VR or DRL schedules. Slower responding represents greater sensitivity to the DRL contingency that reinforces slow responding, but it represents less sensitivity to the VR contingency that reinforces fast responding. Therefore, the within-session decreases in response rates could not be explained by arguing that control by the operant contingency decreased within the session.

The idea that changes in attention produce withinsession changes in response rates requires further study. Although the present results question two potential definitions of that term, attention can be defined in many other ways. For example, if attention becomes more and then less focused on the instrumental task, then the rate at which subjects respond on alternative, "distractor," tasks might decrease and then increase within sessions. Future experiments should test this and other potential definitions of attention.

The present results are compatible with explanations for within-session changes in response rates that are based on concepts such as arousal, satiation, habituation, and interfering responses. For example, if arousal is represented by a multiplicative parameter (Killeen et al., 1978) that applies to all responding, responding should change in similar ways within sessions regardless of whether that responding occurs during $\mathrm{S}+$ or $\mathrm{S}-$. Measures of response accuracy that are based on ratios (e.g., percent correct) should not change systematically within sessions because the multiplicative changes in arousal cancel when ratios are taken. Likewise, interfering responses, such as exploration, might interfere with instrumental responding regardless of whether that responding occurs during $S+$ or $\mathrm{S}-$. Therefore, the within-session changes in response rates would be similar during both of these components (see Figure 2). If interfering responses interfere equally with correct and incorrect responding, then their relative frequency ("accuracy") should not change systematically within sessions (see Figures 1 and 3).

Future experiments should test predictions of potential interpretations of each of the concepts listed above. For example, to date, a number of studies indicate that a simple interpretation of "satiation" cannot account for the within-session changes in response rates under many conditions (e.g., Cannon \& McSweeney, 1995; McSweeney \& Johnson, 1994; Roll, McSweeney, Johnson, \& Weatherly, 1995; Weatherly, McSweeney, \& Swindell, 1995). To illustrate, Roll et al. (1995) varied the caloric content of the reinforcer from 0 to 15.2 calories per gram, varied the size of the reinforcer by a factor of 5 , and varied deprivation for the reinforcer by feeding subjects before the session or by changing their maintenance body weights from $75 \%$ to $95 \%$ of their free-feeding weights. Varying deprivation and caloric density had no effect on the withinsession patterns of responding. Varying reinforcer size altered within-session patterns, but only when the size of the reinforcer increased by a factor of 5 , not by a factor 
of 3. In each experiment, rate of responding averaged over the session changed appropriately with the experimental manipulation. For example, the average rate of responding was faster when subjects responded at $75 \%$ of their free-feeding body weights than at $85 \%$ or $95 \%$ of their free-feeding weights. Therefore, it is unlikely that the experimental manipulations failed to alter the subjects' level of satiation. Future experiments should test other explanations for within-session changes in response rates, such as arousal, interfering responses, and habituation.

Future experiments should also refine the details of the viable concepts. For example, the within-session increases in the discrimination ratios reported in Figure 3 for some schedules are not completely compatible with an explanation in terms of a multiplicative factor. The within-session changes in responding during $\mathrm{S}+$ and $\mathrm{S}-$ were similar but not identical. Therefore, these withinsession changes did not entirely cancel when discrimination ratios were calculated. Future experiments would be required to determine why discrimination ratios changed within sessions. For now, however, these changes indicate either that the factor that produces within-session changes in response rate is not exactly multiplicative during successive discrimination procedures or that the effect of this multiplicative variable is confounded by another variable at different times in the session.

Finding changes in response rate that are unaccompanied by changes in response accuracy (Figures 1 and 3) has implications for identifying the theoretical variables that control performance during DMTS procedures. A detailed discussion of these variables is beyond the scope of this paper. However, one example may be given. It is sometimes assumed that the rate of responding on the sample stimulus provides an independent index of attention to the sample (e.g., Nevin \& Grosch, 1990). It is also assumed that changes in attention to the sample control the accuracy of responding during the choice period (e.g., Nevin \& Grosch, 1990). This argument is questioned by the present dissociations between rate of responding on the sample and accuracy of responding during the choice period, as well as by the weak correlations between these measures that are sometimes reported when measures are averaged over the session (e.g., Nevin \& Grosch, 1990; Santi \& Roberts, 1985). Instead, all of these results suggest that at least some different processes may be at work during the sample presentation and the choice period during DMTS procedures.

\section{REFERENCES}

BindRA, D. (1959). Stimulus change, reactions to novelty and response decrement. Psychological Review, 66, 96-103.

BITTERMAN, M. E. (1960). Toward a comparative psychology of learning. American Psychologist, 15, 704-712.

Bitterman, M. E. (1965). Phyletic differences in learning. American Psychologist, 20, 396-410.

Cannon, C. B., \& MCSweEney, F. K. (1995). Within-session changes in responding when rate and duration of reinforcement vary. Behavioural Processes, 34, 285-292.

DELONG, R. E., \& WASSERMAN, E. A. (1981). Effects of differential re- inforcement expectancies on successive matching-to-sample performance in pigeons. Journal of Experimental Psychology: Animal Behavior Processes, 7, 394-412.

EDHOUSE, W. V., \& WHITE, K. G. (1988). Cumulative proactive interference in animal memory. Animal Learning \& Behavior, 16, 461467.

Feldman, M. P. (1963). A reconsideration of the extinction hypothesis of warm up in motor behavior. Psychological Bulletin, 60, 452459.

Fleshler, M., \& Hoffman, H. S. (1962). A progression for generating variable-interval schedules. Journal of the Experimental Analysis of Behavior, 5, 529-530.

GlanZER, M. (1958). Curiosity, exploratory drive and stimulus satiation. Psychological Bulletin, 55, 302-315.

Groves, P. M., \& Thompson, R. F. (1970). Habituation: A dual process theory. Psychological Review, 77, 419-450.

HeRRNSTEIN, R. J. (1970). On the law of effect. Journal of the Experimental Analysis of Behavior, 13, 243-266.

Herrnstein, R. J., Loveland, D. H., \& Cable, C. (1976). Natural concepts in pigeons. Journal of Experimental Psychology: Animal Behavior Processes, 2, 285-302.

Hodos, W., \& BonBright, J. C., JR. (1972). The detection of visual intensity differences by pigeons. Journal of the Experimental Analysis of Behavior, 18, 471-479.

KilleEn, P. R., Hanson, S. J., \& Osborne, S. R. (1978). Arousal: Its genesis and manifestation as response rate. Psychological Review, $85,571-581$.

MCCARThy, D., \& Voss, P. (1995). Delayed matching-to-sample performance: Effects of relative reinforcer frequency and of signaled versus unsignaled reinforcer magnitudes. Journal of the Experimental Analysis of Behavior, 63, 33-51.

MCSWEENEY, F. K. (1992). Rate of reinforcement and session duration as determinants of within-session patterns of responding. Animal Learning \& Behavior, 20, 160-169.

McSWeeney, F. K., Hatfield, J., \& Allen, T. M. (1990). Withinsession responding as a function of post-session feedings. Behavioural Processes, 22, 177-186.

McSweEney, F. K., \& Hinson, J. M. (1992). Patterns of responding within sessions. Journal of the Experimental Analysis of Behavior, 58, 19-36.

MCSWEeney, F. K., \& Johnson, K. S. (1994). The effect of time between sessions on within-session patterns of responding. Behavioural Processes, 31, 207-218.

MCSWEENEY, F. K., \& Roll, J. M. (1993). Responding changes systematically within sessions during conditioning procedures. Journal of the Experimental Analysis of Behavior, 60, 621-640.

MCSWEeney, F. K., Roll, J. M., \& WeatherLy, J. N. (1994). Withinsession changes in responding during several simple schedules. Journal of the Experimental Analysis of Behavior, 62, 109-132.

NEvin, J. A., \& GROSCH, J. (1990). Effects of signaled reinforcer magnitude on delayed matching-to-sample performance. Journal of Experimental Psychology: Animal Behavior Processes, 16, 298-305.

PAPINI, M. R., \& OVERMIER, J. B. (1985). Partial reinforcement and autoshaping of the pigeon's key-peck behavior. Learning \& Motivation, 16, 109-123.

PaVlov, I. P. (1928). Lectures on conditioned reflexes (W. H. Gantt, Trans.). New York: International Publishers.

ReEse, T. W., \& Hogenson, M. J.(1962). Food satiation in the pigeon. Journal of the Experimental Analysis of Behavior, 5, 239-245.

RoBERTS, W. A. (1972). Short-term memory in the pigeon: Effects of repetition and spacing. Journal of Experimental Psychology, 94, 73-83.

Roll, J. M., MCSweeney, F. K., Johnson, K. S., \& Weatherly, J. N. (1995). Satiety contributes little to within-session decreases in responding. Learning \& Motivation, 26, 323-341.

SANTI, A., \& RoberTs, W. A. (1985). Reinforcement expectancy and trial spacing effects in delayed matching-to-sample by pigeons. $A n$ imal Learning \& Behavior, 13, 274-284.

Tennant, W. A., \& BitTerman, M. E. (1973). Asymptotic free-operant discrimination reversal in the goldfish. Journal of Comparative \& Physiological Psychology, 82, 130-136. 
Weatherly, J. N., McSweeney, F. K., \& SWindell, S. (1995). On the contributions of responding and reinforcement to within-session patterns of responding. Learning \& Motivation, 26, 421-432.

WILKIE, D. M. (1986). Pigeons' spatial memory: V. Proactive interference in the delayed matching of key location paradigm occurs only under restricted conditions. Animal Learning \& Behavior, 14, 257-266.
Woodard, W. T., \& Bitterman, M. E. (1972). Further studies of reversal learning with singly presented stimuli in pigeons and goldfish. Psychonomic Science, 28, 170-172.

(Manuscript received January 27, 1995; revision accepted for publication September 1, 1995.) 